\title{
Radioanatomical examination of the dorsal tubercle and surrounding regions for intraosseous infusions
}

\author{
Selda Aksoy ${ }^{1}$ (D), Mehmet Ali Güner ${ }^{1}$ (D), İnanç Güvenç ${ }^{2}$ (D) , Sedat Bilge ${ }^{3}$ (D), Onur Tezel ${ }^{3}$ (D) \\ ${ }^{1}$ Department of Anatomy, Giilhane Faculty of Medicine, University of Health Sciences, Ankara, Turkey \\ ${ }^{2}$ Department of Radiology, Medical Park Ankara Hospital, Ankara, Turkey \\ ${ }^{3}$ Department of Emergency Medicine, Giilhane Faculty of Medicine, University of Health Sciences, Ankara, Turkey
}

\begin{abstract}
Objectives: The aim of the study was to determine the soft tissue thickness overlying the dorsal tubercle and the relationship with adjacent anatomical structures in the distal radius for using this area as an alternative intraosseous route.

Methods: Contrast-enhanced MR images of 56 adult patients (28 females, 28 males) without any wrist pathology were evaluated. The shape of dorsal tubercle and its relations with neighboring tendons and vessels with a diameter larger than $2 \mathrm{~mm}$ was identified on the axial T1-weighted sections. The soft tissue thickness above the most protruding point of the dorsal tubercle, the distance of the dorsal tubercle to closest tendon on the radial and ulnar sides, as well as its distance to the bone edges on the ulnar and radial sides, and the cortical bone thickness of the radius was evaluated.

Results: The dorsal tubercle had sharp edges in 40 cases (71.4\%), blunt in 12 cases (21.4\%), and hump in 4 (\% 7.1$)$ cases. Branches of dorsal venous plexus were found on its surface in 11 cases, extensor pollicis longus tendon only was found superficial to the dorsal tubercle in 7 cases while both extensor pollicis longus and dorsal venous branches were found in 2 cases.

Conclusion: Dorsal tubercle of the distal radius can be considered as an important alternative route for IO infusions since it can be easily accessed without having a risk of injury to important structures, and can provide effective flow.
\end{abstract}

Keywords: dorsal tubercle; intraosseous infusion; Lister's tubercle; radius

Anatomy 2020;14(3):165-170 @2020 Turkish Society of Anatomy and Clinical Anatomy (TSACA)

\section{Introduction}

Intraosseous infusions (IO) are widely used when the intravenous route is not available. ${ }^{[1]}$ Although the anterior proximal tibia is conventionally used for IO route, ${ }^{[2]}$ the proximal humerus has recently been preferred to reduce the medullary pressure and pain. However, detecting reliable anatomical landmarks in this area is difficult due to the high soft tissue thickness in the proximal humerus region. This method is particularly difficult in people with a prominent deltoid muscle. IO performed on the proximal humerus are reported to have a success rate of $76 \%$ in various studies while this rate is given as $92 \%$ for the proximal tibia. ${ }^{[3]}$ From this point of view, the distal radius where the overlying soft tissue thickness is much lower, can be preferred for IO in the upper extremity. The dorsal tubercle (DT) or Lister's tubercle, which is the most prominent protrusion in the dorsal part of the distal radius, can especially be used as an anatomical mark for many invasive procedures. ${ }^{[4]}$

Since IO are performed in primary health centers, they are mostly conducted without a guide or USG. ${ }^{[8]}$ Therefore, important formations near the intervention area are at risk of injury during invasive procedures. For example, the biceps tendon and branches of the axillary artery are located right next to the greater tubercle serving a potential risk of injury during the interventions targeted to the proximal humerus.

The tibia, humerus, and sternum are of the most common used bones for $\mathrm{IO}^{[8-10]}$ However, the number of studies to determine the safe areas on the distal radius for 
the intraosseous route is inadequate. Although the cortical bone thickness of the distal radius is well known, ${ }^{[1-13]}$ the safety of the region for intraosseous procedures has not been confirmed.

The aim of the study was to determine the soft tissue thickness overlying the DT in the distal radius region and to evaluate the adjacent anatomical structures using magnetic resonance (MR) images, and to determine whether this area can be used as an alternative IO route safely or not.

\section{Materials and Methods}

The contrast-enhanced MR images of 56 adult patients (28 females, 28 males) without any wrist pathology from archives of Ankara Medical Park Hospital were used (Tables 1 and 2). The cases were randomly selected from Radiology archives in terms of their ages, genders and sides, and only one side of each case was included to the study. The age distribution of the gender groups analyzed by two-tailed $\mathrm{t}$ test was statistically similar $(\mathrm{p}=0.81)$.

DICOM images of distal forearm with hand obtained from the MR sections (Siemens Aera ${ }^{\circledR} 1.5 \mathrm{~T}$, slice thickness: $3 \mathrm{~mm}$, both T1 and T2 weighted images) were evaluated with the Adobe Photoshop CC ${ }^{\circledR}$ (Adobe Inc. version 21.2.4 for Windows ${ }^{\circledR}$, San Jose, CA, USA) software. The number of pixels per $10 \mathrm{~mm}$ was calibrated using the scales present in the MR sections. Every 28 pixels corresponded to $10 \mathrm{~mm}$ during this calibration and subsequent measurements were conducted accordingly. Measurements were made with a precision of one tenth of a millimeter.

The long axes of the radius and ulna were arranged parallel to the imaging surface in the axial sections before the measurements if positional anomalies due to rotation were present. Two measurements were performed at different times by the same observer for each case, and the mean values of these measurements were used. Intraobserver reliability was calculated with SPSS $®$ (Version 20.1, Chicago, IL, USA) for all the parameters (intra-class correlation coefficients $>0.910$ ).

The DT was morphologically classified under three groups: sharp, where it peaks with a difference of $2 \mathrm{~mm}$ or more from the other protrusions in the dorsal region; hump, if there is a height difference of less than $2 \mathrm{~mm}$ between the protrusions; and blunt, if two significant protrusions are not present (Figure 1). In each group, the most protruding point of DT was taken as reference for measurements.

The sections where DT was the most prominent were used for measurements. The shape of the DT, the neighboring tendons and the neurovascular structures with a
Table 1

Demographic information of patients.

\begin{tabular}{lcc} 
& Mean \pm SD & Range (min-max) \\
\hline Age $($ year $)$ & $38 \pm 9.64$ & $22-62$ \\
\hline Weight $(\mathrm{kg})$ & $68 \pm 9.24$ & $54-100$ \\
\hline Height $(\mathrm{cm})$ & $167 \pm 7.44$ & $155-189$ \\
\hline BMl $\left(\mathrm{kg} / \mathrm{m}^{2}\right)$ & $24.4 \pm 3.01$ & $18.6-34.1$ \\
\hline
\end{tabular}

BMI: body mass index; SD: standard deviation

Table 2

Gender, age and side distribution of patients.

\begin{tabular}{lccc} 
Gender & Side & Mean age \pm SD (year) & $\mathbf{n}(\%)$ \\
\hline \multirow{2}{*}{ Males } & Right & $38.25 \pm 9.80$ & $16(28.6 \%)$ \\
& Left & $38.70 \pm 9.78$ & $12(21.4 \%)$ \\
\hline \multirow{2}{*}{ Females } & Right & $38.15 \pm 9.33$ & $16(28.6 \%)$ \\
& Left & $38.81 \pm 10.32$ & $12(21.4 \%)$ \\
\hline Total & & & $56(100.0 \%)$ \\
\hline
\end{tabular}

SD: standard deviation; n: number

diameter larger than $2 \mathrm{~mm}$ were identified in the axial T1weighted sections and recorded. The superficial branch of the radial nerve was not taken into consideration since its branches were less than $2 \mathrm{~mm}$ in this area.

The soft tissue thickness above the most protruding point of the DT, the distance between the closest tendon on the radial and ulnar sides, the distance between the DT and the bony edges on the ulnar and radial sides, and the cortical bone thickness of the radius in these sections was measured (Figures 2-4).
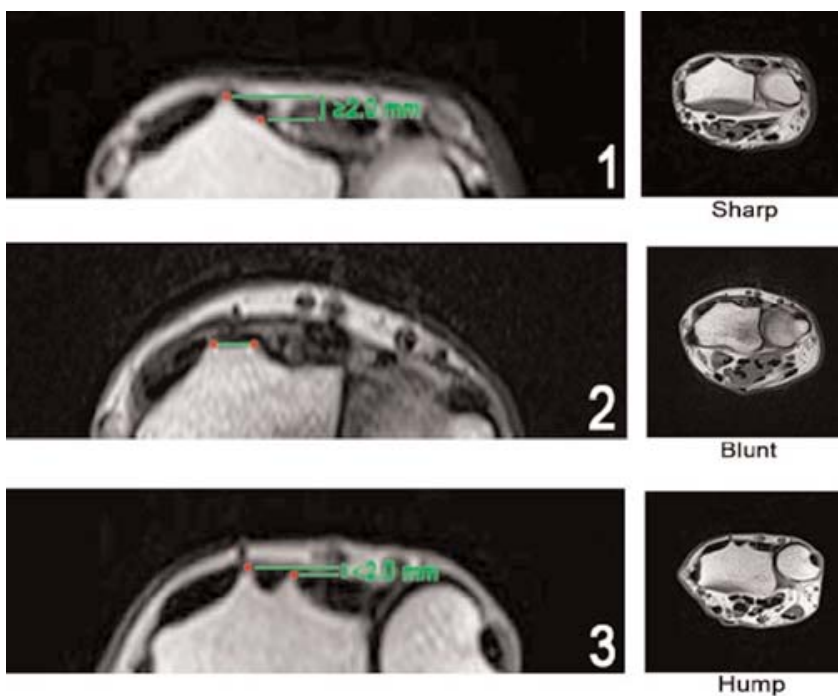

Figure 1. Classification of dorsal tubercle according to its shape as sharp (1), blunt (2), and hump (3). 
Contrast ratios where the medullary and cortical bone could be distinguished most clearly were used in the measurement of the cortical bone thickness of the radius in the $\mathrm{T} 2$-weighted sections in which $\mathrm{DT}$ was the most prominent (Figure 4).

\section{Results}

DT shapes were classified under three groups and were identified as sharp, blunt and hump (Figure 1). The DT was sharp in 40 (71.4\%) (22 females, 18 males) cases, blunt in 12 cases (21.4\%) (6 females, 6 males), and hump in 4 (\%7.1) cases (all male). No significant difference was found between the genders and the morphological type.

The tip of the DT separated the extensor pollicis longus (EPL) and extensor carpi radialis brevis (ECRB) tendons in $41(73.2 \%)$ cases and the EPL and extensor digitorum (ED) tendons in 6 cases $(10.7 \%)$.

The vessels and tendons located superficial to the tip of the DT were identified by examining other sections as well. Vessels with a thickness of $2 \mathrm{~mm}$ or more were only the branches of dorsal venous plexus (DVB) and were found on the surface of the DT in 11 cases ( 3 females, 8 males). EPL tendon was superficial to the DT in 7 cases (5 females, 2 males). Both EPL tendon and DVB was superficial to the DT in 2 cases (all males). No tendon or vein larger than $2 \mathrm{~mm}$ in diameter was found on the DT surface in 36 cases (20 females, 16 males) (Figure 5 and Table 3).

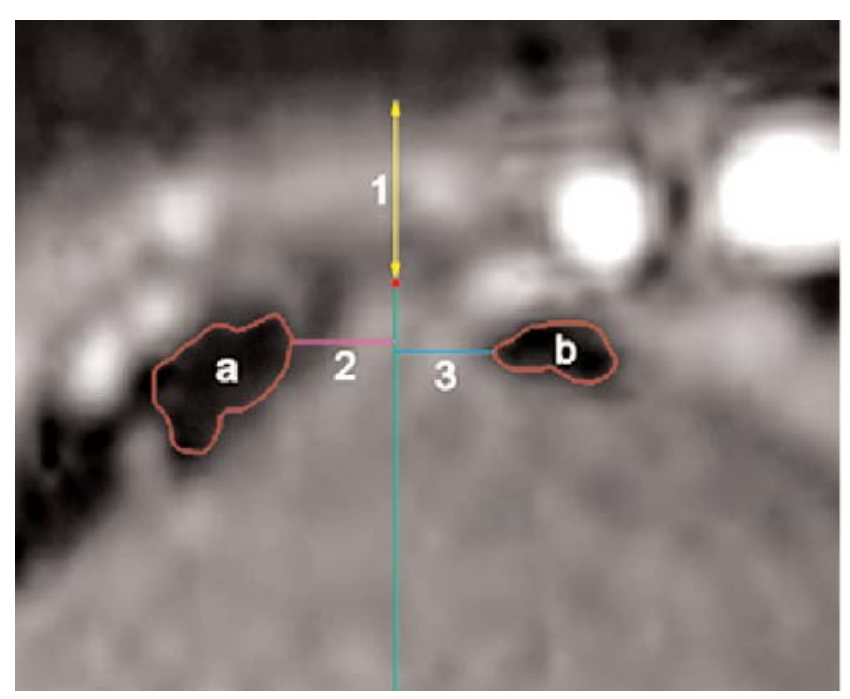

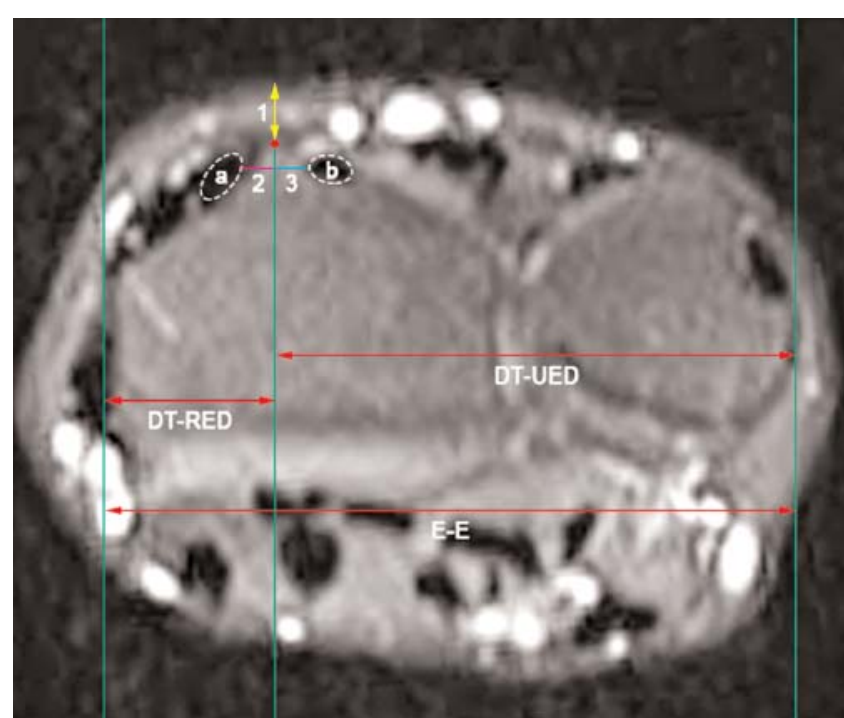

Figure 2. Landmarks used for measurements on an axial wrist MRI. 1: measurement of soft tissue thickness over the tip of the dorsal tubercle; 2: measurement of the horizontal distance between the tip of the dorsal tubercle and the closest tendon on the radial side; 3: measurement of the horizontal distance between the tip of the dorsal tubercle and the closest tendon on the and ulnar side, a: extensor carpi radialis brevis tendon; b: extensor pollicis longus tendon; red dot: tip of the dorsal tubercle, DT-RED: the horizontal distance between the tip of dorsal tubercle and the radial bony edge; DT-UED: the horizontal distance between the tip of the dorsal tubercle and the ulnar bony edge; E-E: edge to edge distance. The green vertical lines were drawn for guidance.

In all cases, the branches originating from the superficial branch of the radial nerve fell below $2 \mathrm{~mm}$ in diameter before the DT level, thus were not considered in measurements.

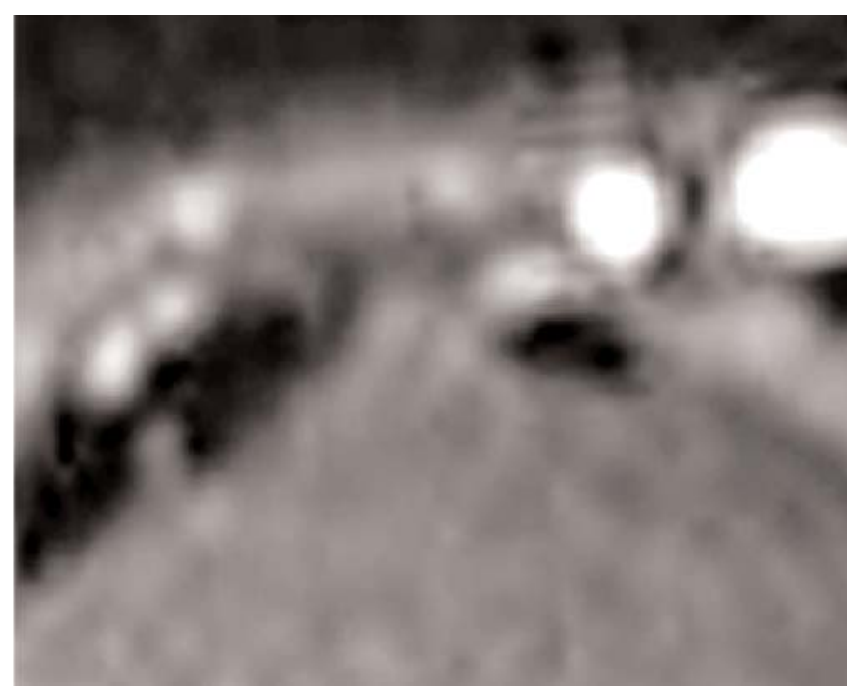

Figure 3. $\times 3$ magnification of Figure 1 focusing on dorsal tubercle to demonstrate the measurements. 1: measurement of soft tissue thickness over the tip of the dorsal tubercle; 2 : measurement of the horizontal distance between the tip of the dorsal tubercle and the closest tendon on the radial side; 3: measurement of the horizontal distance between the tip of the dorsal tubercle and the closest tendon on the and ulnar side, a: extensor carpi radialis brevis tendon; b: extensor pollicis longus tendon; red dot: tip of the dorsal tubercle. The green vertical line was a grid line for guidance. 

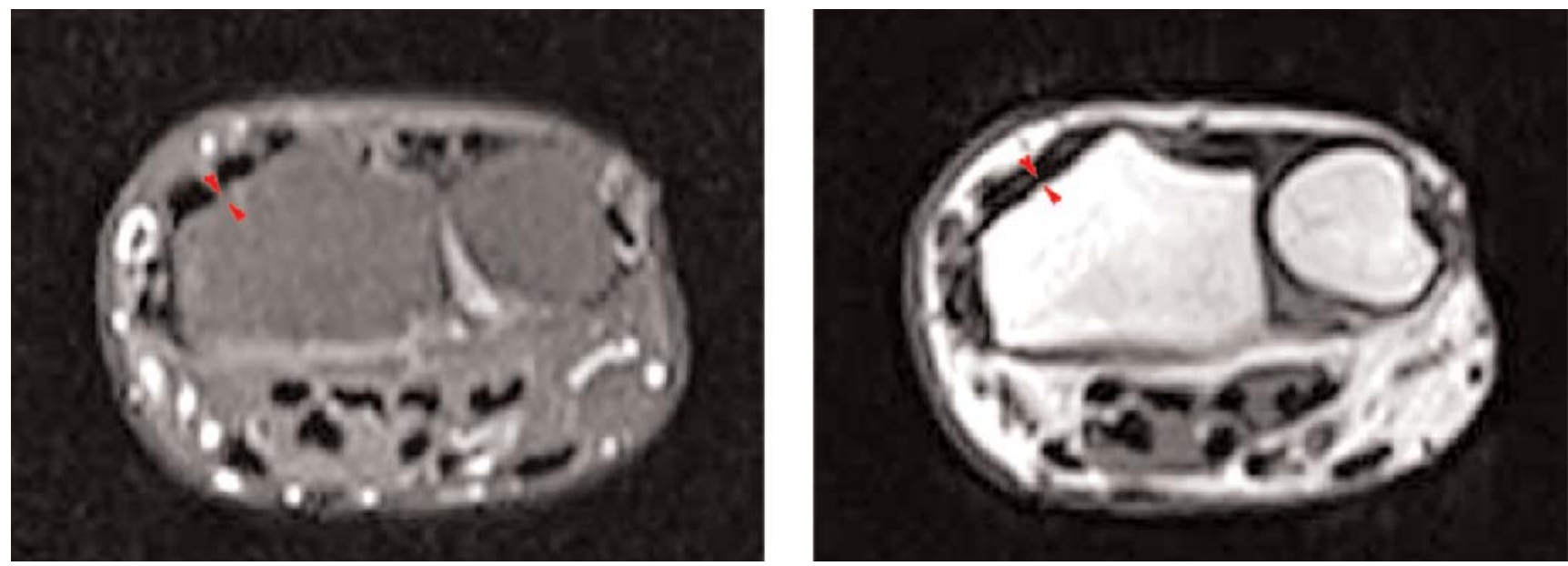

Figure 4. Cortical bone measurements on the distal radius. Cortical bone is demonstrated by red arrows in both T1- and T2-weighted images of the same section.

Table 3

Structures located superficial to the tip of the dorsal tubercle.

\begin{tabular}{lccc} 
& Females & Males & Total \\
\hline Only DVB & 3 & 8 & $11(19.6 \%)$ \\
\hline Only EPL & 5 & 2 & $7(12.5 \%)$ \\
\hline EPL and DVB & 0 & 2 & $2(3.6 \%)$ \\
\hline Total & 8 & 12 & $20(35.7 \%)$ \\
\hline
\end{tabular}

EPL: extensor pollicis longus; DVB: branches of dorsal venous plexus.

The following measurements were done (Figures 2-4) and the results were given in Table 4.

- soft tissue thickness over the tip of the DT

- the horizontal distance between the tip of the DT and the closest tendons on the radial and ulnar sides

- the horizontal distance between the tip of the DT and the ulnar (DT-UED) and radial (DT-RED) bony edges
Table 4

Results of the measurements.

\begin{tabular}{lcccc} 
& $\mathbf{n}$ & Minimum & Maximum & Mean \pm SD \\
\hline STT $(\mathrm{mm})$ & 56 & 1.9 & 10.4 & $4.6 \pm 1.7$ \\
\hline DT-RCT $(\mathrm{mm})$ & 56 & 0.0 & 5.8 & $1.7 \pm 1.2$ \\
\hline DT-UCT $(\mathrm{mm})$ & 56 & 0.0 & 9.8 & $2.3 \pm 1.8$ \\
\hline DT-RED $(\mathrm{mm})$ & 56 & 9.4 & 20.3 & $14.5 \pm 2.3$ \\
\hline DT-UED $(\mathrm{mm})$ & 56 & 28.1 & 40.2 & $34.5 \pm 3.3$ \\
\hline E-E $(\mathrm{mm})$ & 56 & 40.0 & 56.9 & $49.0 \pm 4.1$ \\
\hline CBT $(\mathrm{mm})$ & 56 & 0.7 & 1.8 & $1.1 \pm 0.2$ \\
\hline
\end{tabular}

CBT: cortical bone thickness; DT-RCT: distance of the closest tendon to the dorsal tubercle from the radial side; DT-RED: the horizontal distance between the tip of dorsal tubercle and the radial bony edge; DT-UCT: distance of the closest tendon to the dorsal tubercle from the ulnar side; DT-UED: the horizontal distance between the tip of the dorsal tubercle and the ulnar bony edge; E-E: edge to edge distance; SD: standard deviation; STT: soft tissue thickness over the dorsal tubercle.

- the total horizontal distances between the radial and ulnar bony edges (E-E)

- cortical bone thickness (CBT) of distal radius
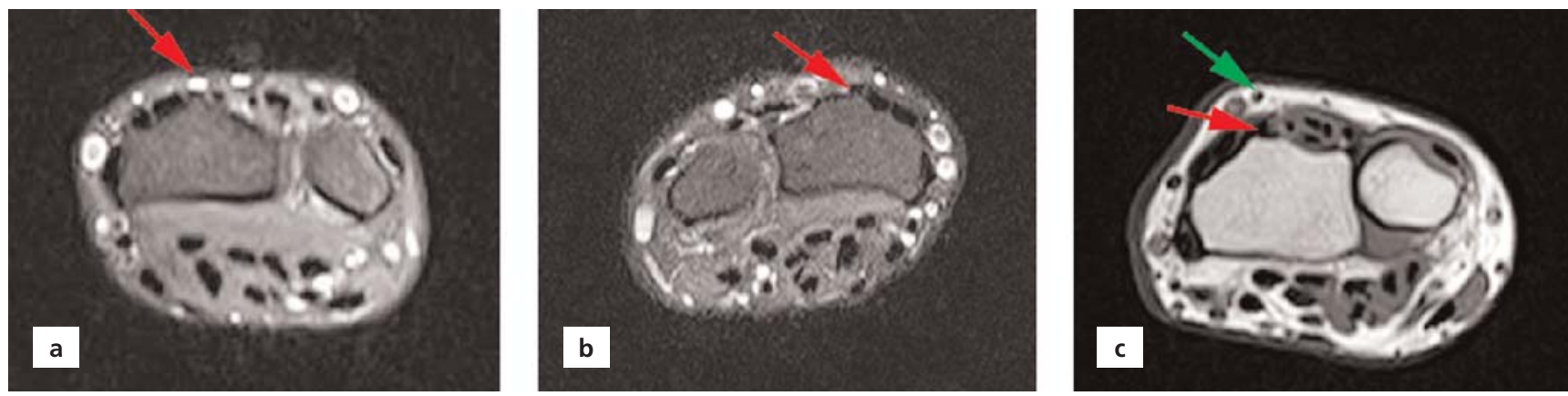

Figure 5. Structures superficial to the dorsal tubercle. (a) a branch of dorsal venous plexus was demonstrated with red arrow; (b) tendon of extensor pollicis longus was demonstrated with red arrow; (c) green and red arrows were used for demonstrating the branch of dorsal venous plexus and extensor pollicis longus tendon respectively. 
There was a positive correlation between soft tissue thickness with body mass index (BMI) of the cases (Pearson correlation coefficient $=0.497, \mathrm{p}=0.000$ ).

\section{Discussion}

The diversity of IO is important in terms of early intervention to the patient under emergency conditions. Various areas on the upper and lower extremities may need to be identified for an effective infusion in the cases of limb losses, burns, and war injuries. ${ }^{[14]}$ In addition to this, new IO routes can become vital when more vascular access is needed in emergency. Therefore, safe and effective intraosseous routes other than the standard anterior tibial approach and proximal humerus may also be needed.

The regions can be selected in accordance with three criteria: easy detection without a guide or by radiological examination, having a proximal location, and the ability to provide an effective fluid flow. ${ }^{[8,1,1,15]}$ Additionally, being close to the central circulation (the heart) can also be considered as an advantage, and the upper extremity and the body may be more suitable in this respect.

The DT and its shape can easily be detected by palpation. Chan et al. ${ }^{[16]}$ divided DT into 3 main types according to its shape and emphasized its relationship with EPL previously. We suggest that DT can be classified according to the characteristics of its tip as sharp, hump and blunt. The DT with a sharp tip could be more suitable for intraosseous infusions and $71 \%$ of the cases were found to be of this type in our study. It may be difficult to reach the DT with a blunt or hump tip and it may be possible to injure an overlying tendon in such cases.

We observed that the structures which can be injured on the DT surface were DVB and the EPL tendon. The DT was superficially covered by the DVB in $20 \%$, by the EPL tendon in $13 \%$, and by both in $3 \%$ of our cases. Considering that the injuries to the DVB are acceptable for such an intervention, the most important structure in the region becomes the EPL tendon, which was located exactly on the DT in $16 \%$ of our cases, in total. Although it was reported that the distance between DT and the closest superficial branch of radial nerve is approximately $16 \mathrm{~mm}$, it is important to note that no neuronal structure thicker than $2 \mathrm{~mm}$ was found adjacent to the DT in our study. ${ }^{[6]}$

The mean soft tissue thickness above the tip of the DT was $4.6 \pm 1.7 \mathrm{~mm}$ in our cases and we suggest that this distance can easily be passed through with a standard IO needle. Rush et al. ${ }^{[1]}$ have reported that the humerus may need a longer needle than the tibia. Hence, the distal radius may be a more preferable point when compared to the greater tubercle of humerus.

The closest adjacent tendons to the tip of the DT on the radial and ulnar sides were ECRB and EPL. However, the tip of the DT separated the EPL and ED tendons in 6 cases $(11 \%)$. The mean distance of the DT to the EPL and ED tendons was $1.7 \pm 1.2 \mathrm{~mm}$ and $2.3 \pm 1.8$ $\mathrm{mm}$, respectively, on the radial and ulnar sides. Adding these two values indicates that a horizontal line of approximately $4.0 \mathrm{~mm}$ will be suitable for IO infusions as intraosseous needles are generally $15 \mathrm{G}$ caliber (the outer diameter of the needle is $1.83 \mathrm{~mm}$ and the inner diameter is $1.37 \mathrm{~mm}) .{ }^{[17]}$

CB thickness is important to prevent the IO needle from damaging the bone. In this context, the mean $\mathrm{CB}$ thickness in the sections where the DT was most distinct was $1.1 \pm 0.2 \mathrm{~mm}$ in our study. Our measurements were performed on standard T1-weighted sections and the T1 sequence may not be sufficient for cortical bone measurements by itself. ${ }^{[18]}$ However, it can be thought that our measurements give an idea regarding CB thickness in the distal radius region. Computed tomography or microstructural studies for detecting $\mathrm{CB}$ thickness at the distal radius region will be more useful. ${ }^{[1,20]} \mathrm{CB}$ has been reported to be approximately $4 \mathrm{~mm}$ for the humeral head and $6 \mathrm{~mm}$ for the tibia diaphysis. ${ }^{[1,21]}$ Since the $\mathrm{CB}$ at distal radius is thinner than the aforementioned structures, the force needed to be applied during infusion should be less as well.

An IO route over the humerus was reported to have a better flow compared to the tibia in a study made on animals. ${ }^{[15]}$ This can be explained by the better vascularization of the humerus and its proximity to the heart. Lamas et al. ${ }^{[2]}$ showed that the distal radius was better supplied by various arteries and pointed DT as the entrance of one of these arteries. ${ }^{[2]}$ Therefore, radius, just like the humerus, can be considered as a better alternative to the tibia in terms of a strong vascular supply and proximity to the heart.

In conclusion, we suggest that the DT of the distal radius can be considered as an important alternative route for IO since it can be easily accessed without having a risk of injury to important structures, and can provide effective flow.

\section{Conflict of Interest}

The authors certify that they have no conflict of interest and no affiliations or involvement in any organization or entity with any financial or non-financial interest in the subject matter or materials discussed in this manuscript. 


\section{Author Contributions}

SA: project development, data acquisition, writing text, critical revision of manuscript; MAG: project development, data acquisition, conducting measurements, writing text; IG: data acquisition, conducting measurements; SB: project development, critical revision of manuscript; OT: project development, writing text, critical revision of manuscript.

\section{Ethics Approval}

The study was approved by the Health Sciences University Ethics Committee (approval no: 19/340, approval date: 22 October 2019).

\section{Funding}

This research did not receive any grants from any funding agency in the public, commercial or not-for-profit sectors.

\section{References}

1. Rush S, Bremer J, Foresto C, Rubin AM, Anderson PI. A magnetic resonance imaging study to define optimal needle length for humeral head IO devices. J Spec Oper Med 2012;12:77-82.

2. Polat O, Oguz AB, Eneyli MG, Comert A, Acar HI, Tuccar E. Applied anatomy for tibial intraosseous access in adults: a radioanatomical study. Clin Anat 2018;31:593-7.

3. Kovar J, Gillum L. Alternate route: the humerus bone - a viable option for IO access. JEMS 2010;35:52-9.

4. Hazani R, Engineer NJ, Cooney D, Wilhelmi BJ. Anatomic landmarks for the first dorsal compartment. Eplasty 2008;8:e53.

5. Smith J, Rizzo M, Finnoff JT, Sayeed YA, Michaud J, Martinoli C. Sonographic appearance of the posterior interosseous nerve at the wrist. J Ultrasound Med 2011;30:1233-9.

6. Ikiz ZAA, Üçerler H. Anatomic characteristics and clinical importance of the superficial branch of the radial nerve. Surg Radiol Anat 2004;26:453-8.

7. Smith DK. Dorsal carpal ligaments of the wrist: normal appearance on multiplanar reconstructions of threedimensional Fourier transform MR imaging. AJR Am J Roentgenol 1993;161:119-25.

8. Dornhofer P, Kellar JZ. Intraosseous vascular access. In: StatPearls [Internet]. Treasure Island (FL): StatPearls Publishing; 2021. PMID: 32119260
9. Blouin D, Gegel BT, Johnson D, Garcia-Blanco JC. Effects of intravenous, sternal, and humerus intraosseous administration of Hextend on time of administration and hemodynamics in a hypovolemic swine model. Am J Disaster Med 2016;11:183-92.

10. Pasley J, Miller CHT, DuBose JJ, Shackelford SA, Fang R, Boswell $\mathrm{K}$, et al. Intraosseous infusion rates under high pressure: a cadaveric comparison of anatomic sites. J Trauma Acute Care Surg 2015;78:295-9.

11. Rausch S, Klos K, Gras F, Skulev HK, Popp A, Hofmann GO, Mückley T. Utility of the cortical thickness of the distal radius as a predictor of distal-radius bone density. Arch Trauma Res 2013;2:115.

12. Bloom RA, Pogrund H, Libson E. Soft-tissue thickness of the wrist. Clin Radiol 1984;35:321-2.

13. Ye C, Guo Y, Zheng Y, Wu Z, Chen K, Zhang X, Xiao L, Chen Z. Distal radial cortical bone thickness correlates with bone mineral density and can predict osteoporosis: a cohort study. Injury 2020;51: 2617-21.

14. Gendron B, Cronin A, Monti J, Brigg A. Military medic performance with employment of a commercial intraosseous infusion device: a randomized, crossover study. Mil Med 2018;183:e216-22.

15. Warren DW, Kissoon N, Sommerauer JF, Rieder MJ. Comparison of fluid infusion rates among peripheral intravenous and humerus, femur, malleolus, and tibial intraosseous sites in normovolemic and hypovolemic piglets. Ann Emerg Med 1993;183-6.

16. Chan WY, Chong LR. Anatomical variants of Lister's tubercle: a new morphological classification based on magnetic resonance imaging. Korean J Radiol 2017;18:957-63.

17. Philbeck TE, Miller LJ, Montez D, Puga T. Hurts so good. Easing IO pain and pressure. JEMS 2010;35:58-62.

18. Du J, Bydder GM. Qualitative and quantitative ultrashort-TE MRI of cortical bone. NMR Biomed 2013;26:489-506.

19. Treece GM, Gee AH, Mayhew PM, Poole KE. High resolution cortical bone thickness measurement from clinical CT data. Med Image Anal 2010;14:276-90.

20. Chen H, Zhou X, Fujita H, Onozuka M, Kubo KY. Age-related changes in trabecular and cortical bone microstructure. Int J Endocrinol 2013;2013:213234.

21. Sadat-Ali M, Elshaboury E, Al-Omran AS, Azam MQ, Syed A, Gullenpet AH. Tibial cortical thickness: a dependable tool for assessing osteoporosis in the absence of dual energy X-ray absorptiopmetry. Int J Appl Basic Med Res 2015;5:21-4.

22. Lamas C, Llusà M, Méndez A, Proubasta I, Carrera A, Forcada P. Intraosseous vascularity of the distal radius: anatomy and clinical implications in distal radius fractures. Hand 2009;4:418-23.

Correspondence to: Selda Aksoy, MD Department of Anatomy, Gülhane Faculty of Medicine, University of Health Sciences, Ankara, Turkey

Phone: +903123043501

e-mail: selda.aksoy@sbu.edu.tr

Conflict of interest statement: No conflicts declared.

This is an open access article distributed under the terms of the Creative Commons Attribution-NonCommercial-NoDerivs 4.0 Unported (CC BY-NCND4.0) Licence (http://creativecommons.org/licenses/by-nc-nd/4.0/) which permits unrestricted noncommercial use, distribution, and reproduction in any medium, provided the original work is properly cited. How to cite this article: Aksoy S, Güner MA, Güvenç İ, Bilge S, Tezel O. Radioanatomical examination of the dorsal tubercle and surrounding regions for intraosseous infusions. Anatomy 2020;14(3):165-170. 